\title{
Improvements of insulin resistance in ovariectomized rats by a novel phytoestrogen from Curcuma comosa Roxb
}

\author{
Mujalin Prasannarong ${ }^{1}$, Vitoon Saengsirisuwan ${ }^{1 *}$, Pawinee Piyachaturawat ${ }^{1}$ and Apichart Suksamrarn²
}

\begin{abstract}
Background: Curcuma comosa Roxb. (C. comosa) is an indigenous medicinal herb that has been used in Thailand as a dietary supplement to relieve postmenopausal symptoms. Recently, a novel phytoestrogen, (3R)-1,7-diphenyl(4E,6E)-4,6-heptadien-3-ol or compound 049, has been isolated and no study thus far has investigated the role of $C$. comosa in preventing metabolic alterations occurring in estrogen-deprived state. The present study investigated the long-term effects (12 weeks) of C. comosa hexane extract and compound 049 on insulin resistance in prolonged estrogen-deprived rats.

Methods: Female Sprague-Dawley rats were ovariectomized (OVX) and treated with C. comosa hexane extract (125 mg, $250 \mathrm{mg}$, or $500 \mathrm{mg} / \mathrm{kg}$ body weight (BW)) and compound 049 (50 mg/kg BW) intraperitoneally three times per week for 12 weeks. Body weight, food intake, visceral fat weight, uterine weight, serum lipid profile, glucose tolerance, insulin action on skeletal muscle glucose transport activity, and GLUT-4 protein expression were determined.
\end{abstract}

Results: Prolonged ovariectomy resulted in dyslipidemia, impaired glucose tolerance and insulin-stimulated skeletal muscle glucose transport, as compared to SHAM. Treatment with C. comosa hexane extract and compound 049, three times per week for 12 weeks, markedly reduced serum total cholesterol and low-density lipoprotein levels, improved insulin sensitivity and partially restored uterine weights in ovariectomized rats. In addition, compound 049 or high doses of C. comosa hexane extract enhanced insulin-mediated glucose uptake in skeletal muscle and increased muscle GLUT-4 protein levels.

Conclusions: Treatment with C. comosa and its diarylheptanoid derivative improved glucose and lipid metabolism in estrogen-deprived rats, supporting the traditional use of this natural phytoestrogen as a strategy for relieving insulin resistance and its related metabolic defects in postmenopausal women.

\section{Background}

Insulin resistance syndrome is a complex metabolic abnormality of peripheral tissues in response to insulin. The main features of this syndrome include insulin resistance of skeletal muscle glucose metabolism, impaired glucose tolerance, compensatory hyperinsulinemia, essential hypertension, central obesity, and atherogenic dyslipidemia [1]. Postmenopausal women are at a greater risk for developing type 2 diabetes [2], a metabolic disorder characterized by glucose intolerance and

\footnotetext{
*Correspondence: scvss@mahidol.ac.th

'Department of Physiology, Faculty of Science, Mahidol University, Rama VI Road, Bangkok 10400, Thailand

Full list of author information is available at the end of the article
}

insulin resistance. These metabolic conditions in postmenopausal women are usually accompanied by weight gain, obesity, and increased inflammation [3-5]. In addition, an increase in mortality associated with type 2 diabetes and cardiovascular disease has been directly attributed to insulin resistance and hyperinsulinemia [6]. Importantly, estrogen replacement can attenuate the increased risk for type 2 diabetes in postmenopausal women and improve whole body glucose metabolism $[2,7]$, suggesting a critical role of estrogen in regulating glucose homeostasis. However, clinical studies on hormone replacement therapy in postmenopausal women have raised concerns about an increased risk of breast cancer and an unacceptable rate of unfavorable

\section{Biomed Central}


outcomes [8]. Therefore, the search for novel estrogen replacement strategies is an issue of increasing importance for postmenopausal women.

Phytoestrogens are naturally occurring non-steroidal plant-derived compounds with diverse structures which are found in many fruits, vegetables, and grains [9]. Studies on dietary phytoestrogens intake in postmenopausal women have indicated that high phytoestrogens intake is associated with a favorable metabolic cardiovascular risk profile, such as reduced plasma lipids and decreased aortic stiffness $[10,11]$. In addition, the use of phytoestrogens as an alternative intervention has been supported by evidences that incidence of menopausal symptoms and of breast and endometrial cancers are lower in Asian women who have a diet rich in soy products $[12,13]$. Plant-derived phytoestrogens are, therefore, considered to be an alternative remedy to prevent the development of metabolic defects in postmenopausal women.

Curcuma comosa Roxb. (Zingiberaceae) has been traditionally used in indigenous medicine in Thailand as a dietary supplement to relieve a variety of unpleasant peri- and postmenopausal symptoms. The hexane extract of $C$. comosa rhizome exhibited hypocholesterolemic $[14,15]$ and anti-inflammatory activity $[16,17]$. Furthermore, treatment with $C$. comosa hexane extract improved the spatial memory of post-training [18] and effectively prevented bone loss in ovariectomized rodents [19]. The unique pharmacological actions of $C$. comosa underscore its therapeutic potential in relieving menopausal symptoms. Recently, the hexane extract of C. comosa and its isolated compound, a diarylheptanoid or (3R)-1,7-diphenyl-(4E,6E)-4,6-heptadien-3-ol (hereafter referred to as compound 049) have been demonstrated to have estrogenic activity [20,21]. Despite the long-term and widespread use of C. comosa extract, to date, no studies have been conducted to investigate its potential to reduce the risks of diabetes and cardiovascular disease in postmenopausal women. Therefore, the present study was undertaken to investigate the longterm (12 weeks) effects of C. comosa extract and compound 049 on metabolic alterations in rats with ovariectomy-induced insulin resistance. The results of this study provide mechanistic insight into the favorable effects of these compounds being used as an alternative strategy for relieving insulin resistance and its related metabolic defects in postmenopausal women.

\section{Materials and methods Chemicals}

$2-\left[1,2-{ }^{3} \mathrm{H}\right]$ deoxyglucose $(300 \mu \mathrm{Ci} / \mathrm{mmol}),\left[\mathrm{U}^{14} \mathrm{C}\right.$ ] mannitol $(0.8 \mu \mathrm{Ci} / \mathrm{mmol})$, and Ultima Gold ${ }^{\mathrm{TM}}$ scintillation cocktail were obtained from PerkinElmer Life Sciences (Boston, MA, USA), chemicals for the bicinchoninic acid (BCA) protein assay and bovine serum albumin were obtained from Sigma Chemical (St. Louis, MO, USA), Human R insulin (Insulin, Human Recombinant) from Eli Lilly (Indianapolis, IN, USA), ketamine from Gedeon Richter (Budapest, Hungary), xylazine from Farvet Laboratories (Bladel, The Netherlands), polyclonal anti-GLUT-4 antibody from Santa Cruz Biotechnology (Santa Cruz, CA, USA), and rabbit horseradish peroxidase-conjugated (IgG-HRP) secondary antibody and enhanced chemiluminescence (ECL) reagent from Cell Signaling Technology (Beverly, MA, USA). The glucose assay kit was obtained from Gesellschaft fur Biochemica und Diagnostica (Wiesbaden, Germany) and insulin radioimmunoassay kit from Linco Research (St. Charles, MO, USA). Precast polyacrylamide gels were purchased from Pierce (Perbio Science, Cambrigde, England).

\section{C. comosa plant extract and compound 049 isolation}

C. comosa rhizomes were collected from the Kampaengsaen district, Nakorn Pathom province, Thailand. A voucher herbarium specimen has been deposited at the Department of Plant Science, Faculty of Science, Mahidol University, Bangkok (SCMU No. 300) [22]. Preparation of the C. comosa plant extracts were performed as previously reported [20]. Briefly, the rhizomes were sliced, dried, and ground to a powder. The powder was successively extracted with $n$-hexane and the solvent was removed in vacuo. For the hexane extract, a palebrown viscous oil was obtained. This hexane extract was dissolved in corn oil for animal treatment. Characterization and standardization of the extract used in this study was conducted using reversed-phase HPLC (column: Prodigy ODS-3, $250 \mathrm{~mm} \times 4.6 \mathrm{~mm}, 5 \mu, 100 \AA$ A mobile phase: water-acetonitrile; detection at $260 \mathrm{~nm})$, revealing a major diarylheptanoid (23.9\%), (3R)-1,7diphenyl-(4E,6E)-4,6-heptadien-3-ol (compound 049) (Figure 1). Compound 049 was isolated from the hexane extract as a major component by repeated silica gel column chromatography eluting with hexane/dichloromethane; each step utilized an increasing quantity of the more polar solvent.

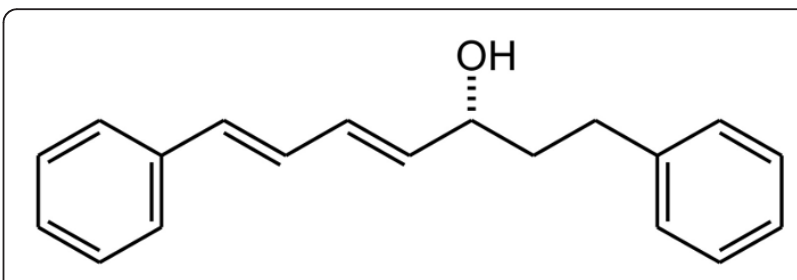

Figure 1 Structure of (3R)-1,7-diphenyl-(4E,6E)-4,6-heptadien-3ol: compound 049 . 


\section{Animals and treatments}

Animal procedures were approved by the Animal Care and Use Committee, Faculty of Science, Mahidol University, in accordance with the International Guiding Principles for Biomedical Research Involving Animals of Council for International Organizations of Medical Sciences (CIOMS). Adult female Sprague-Dawley rats (8-weeks-old), weighing between 180-200 g, supplied by the National Laboratory Animal Center, Thailand, were housed individually in $8 \times 10$ inch hygienic hanging metabolic cages at the Center of Animal Facilities, Faculty Science, Mahidol University. Animals were given standard rat chow and water ad libitum. The housing unit was maintained at $22-23^{\circ} \mathrm{C}$ with a $12 / 12 \mathrm{~h}$ light/ dark cycle. Body weight was recorded every other day. The amount of food intake for each animal was measured over a $24 \mathrm{~h}$ period, and measurements were conducted at least 3 times per week. Rats were randomly assigned to either sham operation (SHAM, $\mathrm{n}=8$ ) or bilateral ovariectomy (OVX, $\mathrm{n}=40)$. Animals were allowed to recuperate for 7 days after surgery. Ovariectomized animals were randomly divided into one of the following five groups: OVX-control (OVX), OVX receiving $C$. comosa hexane extract at a dose of $125 \mathrm{mg} / \mathrm{kg}$ body weight $(\mathrm{BW})(\mathrm{OVX}+\mathrm{C}-125)$, OVX receiving 250 $\mathrm{mg}$ C. comosa extract/kg BW (OVX + C-250), OVX receiving $500 \mathrm{mg} C$. comosa extract $/ \mathrm{kg} \mathrm{BW}(\mathrm{OVX}+\mathrm{C}$ $500)$, and OVX receiving (3R)-1,7-diphenyl-(4E,6E)-4,6heptadien-3-ol (compound 049) at dose of $50 \mathrm{mg} / \mathrm{kg}$ BW (OVX + 049). The C. comosa-treated animals were intraperitoneally administered $0.1 \mathrm{~mL}$ of the C. comosa hexane extract or compound 049 diluted in corn oil. SHAM and OVX-control rats received vehicle $(0.1 \mathrm{~mL}$ corn oil). Treatment and vehicle were administered three times per week for 12 weeks.

\section{Determination of whole body insulin sensitivity}

Oral glucose tolerance test (OGTT) was performed to assess insulin sensitivity at the whole-body level. Following a 12-week treatment period, an OGTT was performed on each animal. In the evening (1800 h) of the day before the test, rats were food-restricted to $4 \mathrm{~g}$ of chow. On the day of the test (0900 h), blood sample were collected from tail veins before and after glucose feeding ( $1 \mathrm{~g} / \mathrm{kg} \mathrm{BW})$ at 15, 30, 60, and $90 \mathrm{~min}$. Blood sample were mixed with EDTA and centrifuged at $13000 \mathrm{~g}$ at $4^{\circ} \mathrm{C}$ for $1 \mathrm{~min}$. Plasma was kept at $-80^{\circ} \mathrm{C}$ and used for glucose and insulin determination. The area under the curve for glucose (glucose AUC) or insulin (insulin AUC) was calculated. Subsequently, the glucose-insulin (G-I) index was calculated, as the product of the respective glucose and insulin AUCs, and is inversely related to whole-body insulin sensitivity [23].

\section{Assessment of muscle glucose transport activity}

As skeletal muscle is the major tissue accounting for 70$85 \%$ of whole-body glucose disposal following a glucose challenge [24], insulin action on glucose transport activity was determined in skeletal muscle under basal and insulin-stimulated conditions using 2-deoxy- $\left[{ }^{3} \mathrm{H}\right]$-glucose (2-DG) uptake. Five days after OGTT, animals were food-restricted as described above. At $0800 \mathrm{~h}$, animals were weighed and anesthetized by intraperitoneal administration of a mixture of ketamine $(50 \mathrm{mg} / \mathrm{kg} \mathrm{BW})$ and xylazine $(10 \mathrm{mg} / \mathrm{kg} \mathrm{BW})$. Soleus muscle was isolated, divided into two portions of approximately 20-25 $\mathrm{mg}$, and incubated for $60 \mathrm{~min}$ at $37^{\circ} \mathrm{C}$ in $3 \mathrm{~mL}$ of oxygenated Krebs-Henseleit Buffer (KHB) supplemented with $8 \mathrm{mM}$ D-glucose, $32 \mathrm{mM}$ D-mannitol and $0.1 \%$ radioimmunoassay-grade bovine serum albumin (BSA). One strip of soleus muscle was incubated in the absence of insulin, and the other strip in the presence of a maximally effective concentration of insulin $(2 \mathrm{mU} / \mathrm{mL})$. Flasks were continuously gassed with a mixture of $95 \%$ $\mathrm{O}_{2}$ and $5 \% \mathrm{CO}_{2}$ throughout the incubation and transport study procedures. After the first incubation period, each muscle strip was rinsed for $10 \mathrm{~min}$ at $37^{\circ} \mathrm{C}$ in 3 $\mathrm{mL}$ of oxygenated $\mathrm{KHB}$ containing $40 \mathrm{mM}$ D-mannitol, $0.1 \%$ BSA and insulin (for the muscle strip in the presence of insulin). Each muscle strip was then incubated for $20 \mathrm{~min}$ at $37^{\circ} \mathrm{C}$ in $2 \mathrm{~mL}$ of $\mathrm{KHB}$ containing $1 \mathrm{mM}$ $2-\left[1,2-{ }^{3} \mathrm{H}\right]$ deoxyglucose (2-DG), $39 \mathrm{mM}\left[\mathrm{U}^{-14} \mathrm{C}\right] \mathrm{man}-$ nitol, $0.1 \% \mathrm{BSA}$ and insulin (for the muscle strip in the presence of insulin). At the end of the incubation period, muscle strips were removed and trimmed of excess fat and connective tissue, immediately frozen with liquid nitrogen and weighed. Frozen muscles were solubilized in $0.5 \mathrm{~mL}$ of $0.5 \mathrm{M} \mathrm{NaOH}$, and $10 \mathrm{~mL}$ of scintillation cocktail was added. Specific intracellular accumulation of 2-DG was determined as previously described [25] using mannitol to correct for extracellular accumulation of 2-DG. Glucose transport activity was measured by determination of the intracellular accumulation of 2-DG (pmol/mg muscle wet weight/20 min). Contralateral soleus muscle was also removed, trimmed of fat and connective tissue, quickly frozen in liquid nitrogen, and used for GLUT-4 protein level determination.

\section{Serum lipid measurements}

Following muscle dissection, blood was collected from the abdominal vein. Whole blood was allowed to clot and then centrifuged at $3000 \mathrm{~g}$ for $20 \mathrm{~min}$ to obtain serum. Serum levels of total cholesterol (TC), high-density lipoprotein cholesterol (HDL), and low-density lipoprotein cholesterol (LDL) were measured by enzymatic methods using an automated analyzer (Dimension RxL Max, DADE Behring, Marburg, Germany). Immediately after blood sample collection, visceral fat was collected 
from the superficial area covering the alimentary tract, and the uterus was removed and weighed.

\section{Muscle GLUT-4 protein content}

Glucose uptake into skeletal muscle under insulin-stimulated condition is mediated by GLUT-4 protein [26]. To examine whether changes in insulin action on skeletal muscle glucose transport due to C. comosa treatment is associated with GLUT-4 protein expression, muscle GLUT-4 protein levels were evaluated. Portions of soleus muscle were homogenized as previously described [27]. These homogenates were used for total protein determination, solubilized, separated by electrophoresis using a $12 \%$ pre-cast polyacrylamide gel and transferred onto nitrocellulose paper. Protein blots were incubated with polyclonal anti-GLUT-4 antibody, GAPDH and subsequently with IgG-HRP secondary antibody. Protein bands were visualized by ECL on hyper film. Images were digitized and band intensities quantified using Image Master Totallab Software, version 3.0 (Amersham Pharmacia Biotech, Sweden).

\section{Statistical analysis}

All values were expressed as the mean \pm SE. Differences among groups were determined using a one-way analysis of variance (ANOVA) with Tukey's multiple comparison post-test using SPSS program version 16.0. A value of $P<0.05$ was considered to be statistically significant.

\section{Results}

\section{Body and tissue weight and food intake}

Twelve weeks following ovariectomy, OVX rats displayed significant weight gain compared to SHAM animals (Figure 2A). Body weight gain observed in OVX rats was significantly reversed by $C$. comosa extract treatment. Food intake, based on the accumulated average daily food intake throughout the 12-week experimental period, was significantly higher in OVX rats compared to either SHAM rats or OVX rats treated with $C$. comosa extract (Figure $2 \mathrm{~B}$ ). In contrast to the effects of $C$. comosa extract, compound 049 treatment did not affect body weight gain or food intake in OVX rats. Comparison of OVX rats with SHAM rats showed a $22 \%$ increase in visceral fat content, which was significantly reversed by treatment with either C. comosa extract or compound 049 (Figure 2C). The reduction in uterine weight in OVX rats was also partially recovered by treatment with either C. comosa extract or compound 049 (Figure 2D).

\section{Serum lipid profile}

Compared to SHAM rats, OVX rats displayed a significant increase in TC (36\%) and LDL (45\%), but not HDL, whereas treatment with either $C$. comosa extract or compound 049 significantly reduced both TC levels (19-37\%) and LDL levels (27-45\%) (Figures 3A-C). C. comosa extract or compound 049 treatment resulted in a significant reduction in the LDL/TC ratio in OVX rats (Figure 3E). Interestingly, treatment with either $C$. comosa extract or compound 049 significantly improved the HDL/TC ratio when compared to the SHAM and OVX groups (Figure 3D).

\section{OGTT response}

Following glucose feeding $(1 \mathrm{~g} / \mathrm{kg} \mathrm{BW})$, there was no significant difference in plasma glucose levels among all groups throughout the experimental period (Figure 4A). However, 15-min after glucose challenge, plasma insulin levels in OVX rats were higher than those in other experimental groups (Figure 4B). Compared with the SHAM group, OVX rats displayed a significant rise in both insulin AUC (38\%, Figure 4D) and G-I index (49\%, Figure 4E). These elevated insulin AUC and G-I index values observed in the OVX group were reduced following treatment with either C. comosa extract (39-44\%, Figure 4D) or compound 049 (28-34\%, Figure 4E).

\section{Muscle glucose transport and GLUT-4 protein levels}

Skeletal muscle is the major tissue responsible for whole-body glucose disposal following a glucose challenge [24]. Thus, the effects of C. comosa and compound 049 treatment on insulin-stimulated glucose transport activity and on total GLUT-4 protein levels in skeletal muscle were studied. Basal 2-deoxy- $\left[{ }^{3} \mathrm{H}\right]$-glucose (2-DG) uptake was comparable among the experimental groups (Figure 5A). Compared to the SHAM group, insulin-mediated 2-DG transport rates in soleus muscle isolated from OVX rats was reduced by $35 \%$ (Figure 5B). A significant improvement in insulinmediated 2-DG uptake was observed in the OVX rats receiving either C-500 (16\%) or compound 049 (45\%) (Figure 5B). Twelve weeks following ovariectomy, total GLUT-4 protein levels in soleus muscle were reduced by $33 \%$ in OVX rats (Figure $5 \mathrm{C}$ ). Treatment with either C-500 or compound 049 significantly restored GLUT-4 protein levels in soleus muscle by $17 \%$ and $47 \%$, respectively (Figure 5C).

\section{Discussion}

The present study demonstrated the protective effects of C. comosa, a novel natural phytoestrogen, against the risks of diabetes and cardiovascular disease in rats under estrogen-deprivation conditions. The evidence presented in this study corroborates the traditional use of $C$. comosa in relieving unpleasant symptoms in postmenopausal women including the metabolic defects. Moreover, this study indicates that these favorable effects observed following C. comosa extract treatment in the 

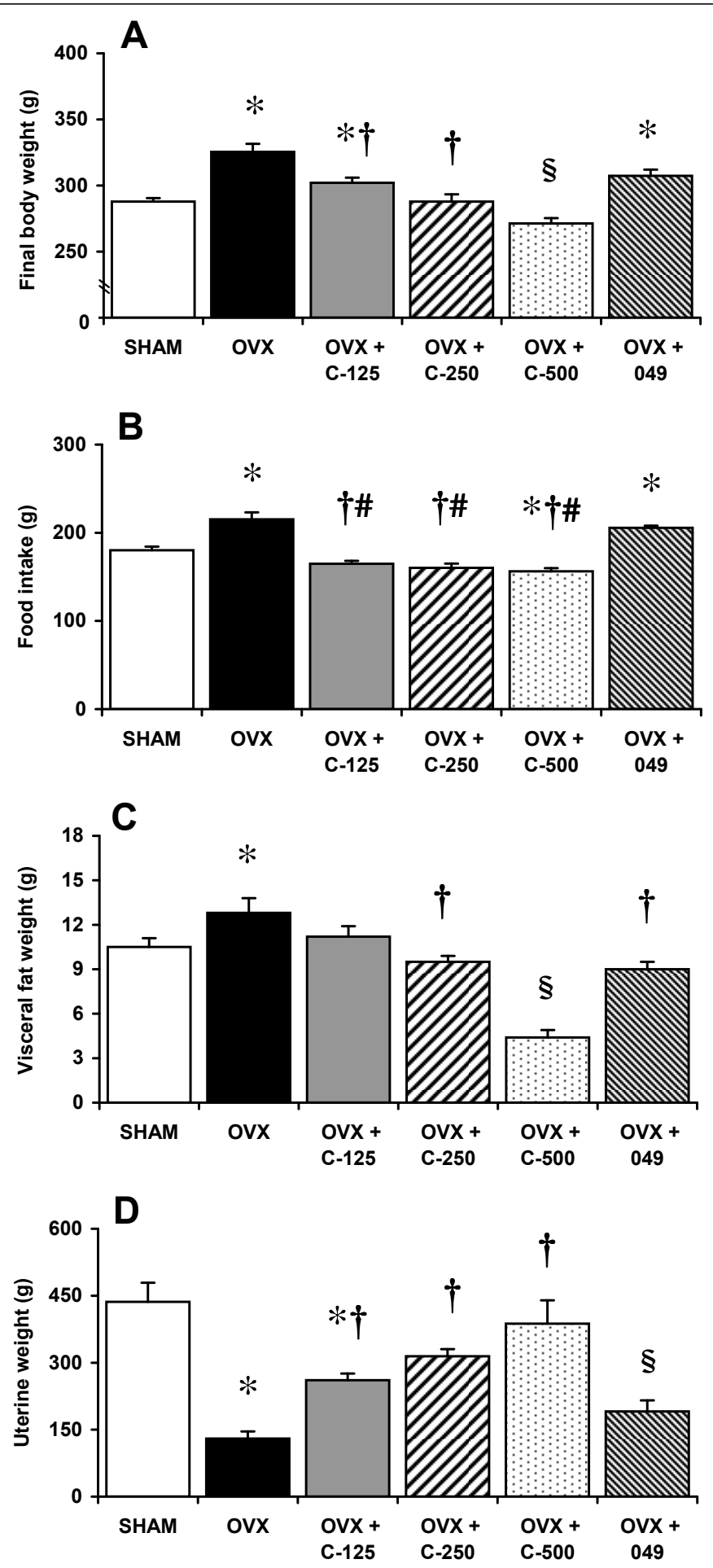

Figure 2 Final body weight, food intake, visceral fat weight and uterine weight of sham operated control (SHAM) and ovariectomized (OVX) rats treated with or without C. comosa hexane extract at $125 \mathrm{mg}(\mathrm{OVX}+\mathrm{C}-125), 250 \mathrm{mg}(\mathrm{OVX}+\mathrm{C}-250)$, and $500 \mathrm{mg}(\mathrm{OVX}+\mathrm{C}-$ 500) per kg body weight or $50 \mathrm{mg}$ of compound 049 per $\mathbf{k g}$ body weight (OVX + 049). Final body weight (A); accumulated amount of food intake (B); visceral fat weight (C); uterine weight (D). Values are reported as the mean \pm SE for 8 animals/group. ${ }^{* P}<0.05$ vs. SHAM group; † $P<0.05$ vs. OVX group; $\# P<0.05$ vs. OVX $+049 ; \S P<0.05$ vs. all other groups. 

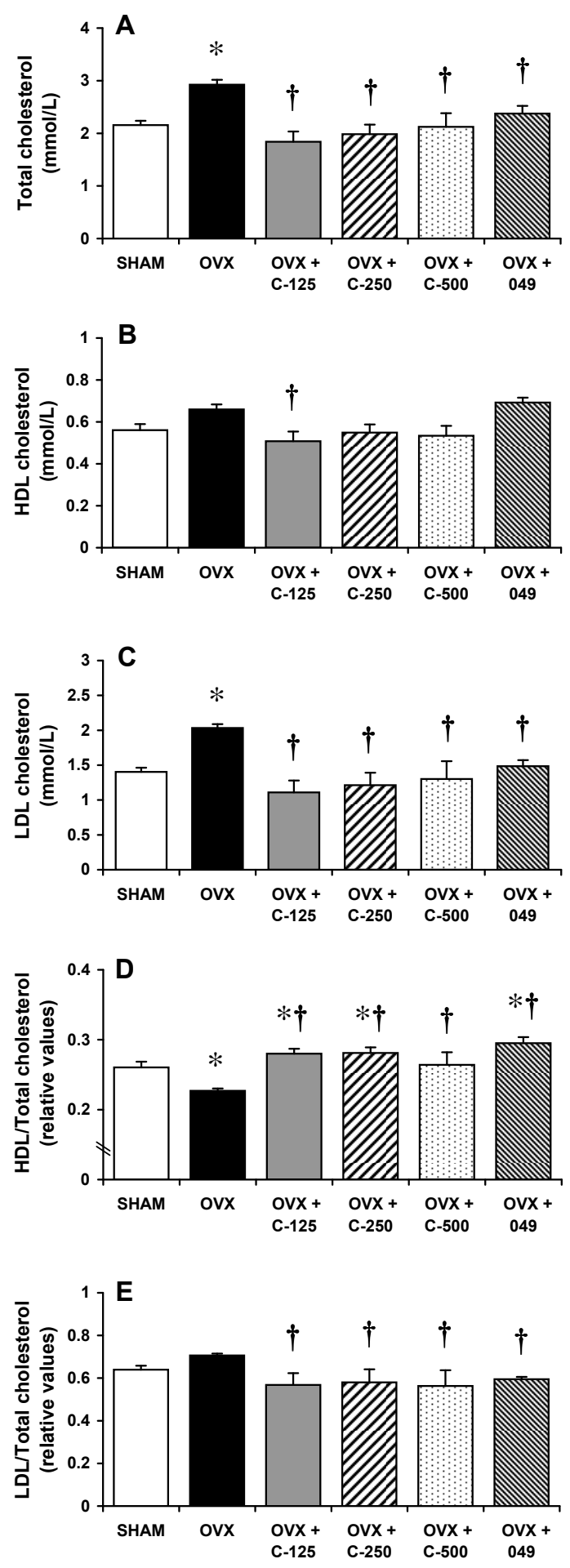

Figure 3 Serum lipid levels of sham operated control (SHAM) and ovariectomized (OVX) rats treated with or without C. comosa hexane extract or compound 049. Animals are as described in legend of Figure 2. (A) total; (B) high-density lipoprotein (HDL) cholesterol; (C) low-density lipoprotein (LDL) cholesterol; (D) ratio of HDL to total cholesterol (HDL/total); and (E) ratio of LDL to total cholesterol (LDL/total). Values are reported as the mean $\pm \mathrm{SE}$ for 8 animals/group. ${ }^{*} P<0.05$ vs. SHAM group; $\boldsymbol{t} P<0.05$ vs. OVX group. 

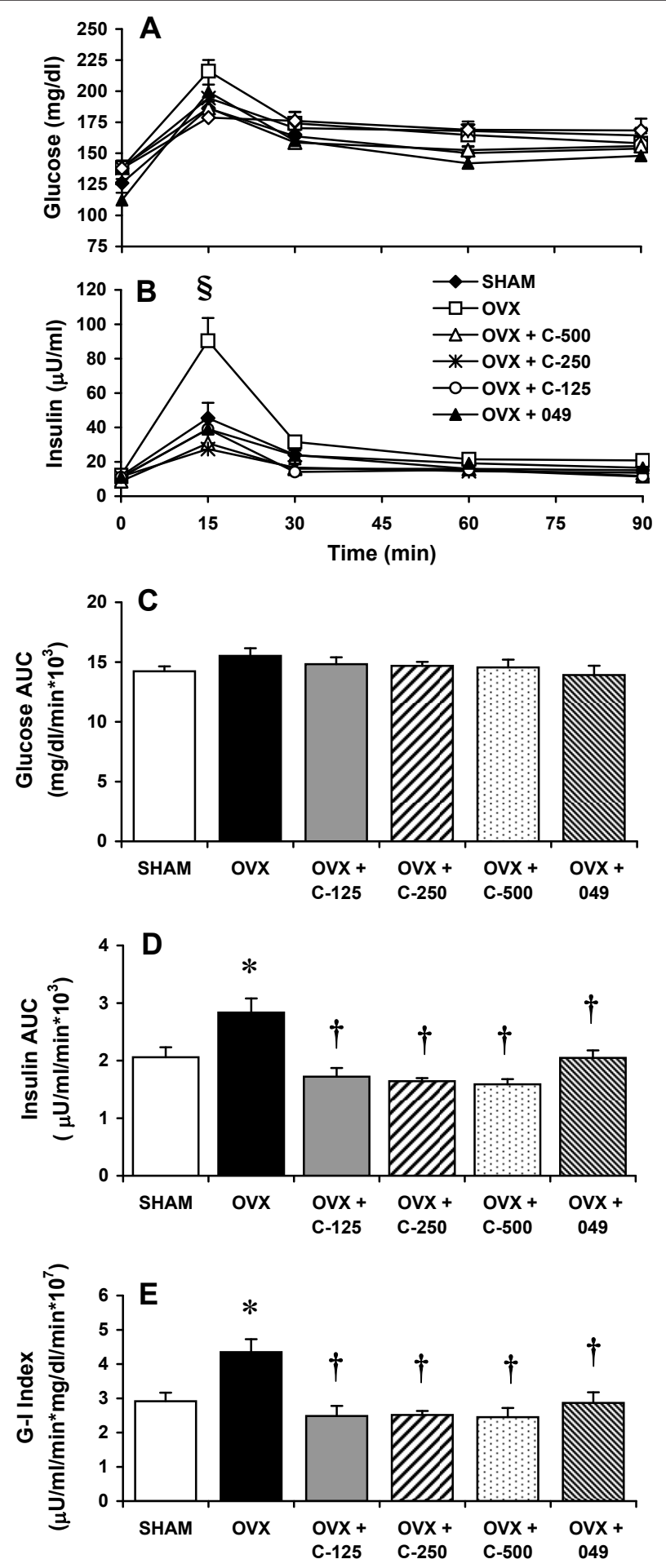

Figure 4 Glucose tolerance tests of sham operated control (SHAM) and ovariectomized (OVX) rats treated with or without C. comosa hexane extract or compound 049. Animals are as described in legend of Figure 2. Glucose (A) and insulin (B) responses; area under the curve (AUC) for glucose (C) and insulin (D); glucose-insulin (G-I) index (E). G-I index is the product of glucose AUC and insulin AUC for each individual animal. Values are reported as the mean $\pm \mathrm{SE}$ for $7-8$ animals/group. ${ }^{*} P<0.05$ vs. SHAM group; $\mathrm{t} P<0.05$ vs. OVX group; $\S P<0.05$ vs. all other groups. 

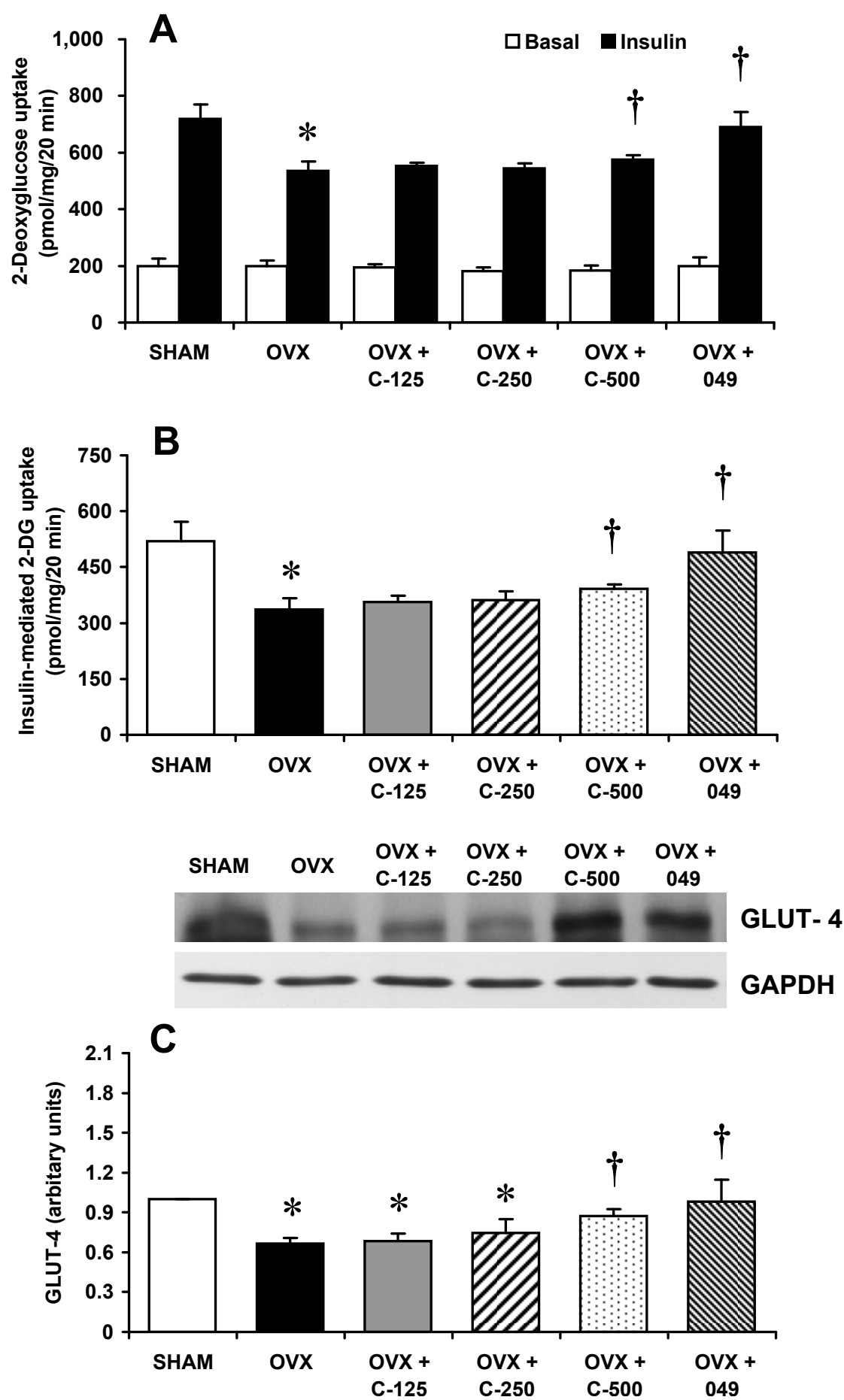

Figure $\mathbf{5}$ In vitro rate of 2-deoxyglucose uptake and GLUT-4 protein content in the soleus muscles of sham operated control (SHAM) and ovariectomized (OVX) rats treated with or without C. comosa hexane extract or compound 049. Animals are as described in legend of Figure 2. (A) 2-deoxyglucose uptake in the absence (blank bar) and presence (filled bar) of insulin (2 mU/ml); (B) net increase above basal level for 2-deoxyglucose uptake due to insulin; (C) whole muscle GLUT-4 protein levels. GLUT-4 levels were normalized by GAPDH. Values are reported as the mean \pm SE for $7-8$ animals/group. ${ }^{*} P<0.05$ vs. SHAM group; $+P<0.05$ vs. OVX group. 
insulin-resistant condition can be attributed to multiple actions including its estrogenic and anti-inflammatory properties, and its diarylheptanoid derivative is at least accounted for the effects.

The role of estrogen in the regulation of glucose homeostasis has been shown previously. For example, postmenopausal women are at risk for increased incidence of obesity, type 2 diabetes, cardiovascular disease, and insulin resistance syndrome $[5,28,29]$, whereas estrogen therapy reduces the incidence of insulin resistance and type 2 diabetes risks [30,31]. Insulin resistance develops when there is no estrogen in aromatase-knockout mice [32]. Hepatic insulin resistance and impaired skeletal muscle GLUT-4 expression are accounted for the impaired glucose tolerance and reduced insulin sensitivity in estrogen receptor alpha $(\mathrm{ER} \alpha)$ knockout mice $[33,34]$. Due to ovarian hormone depletion, OVX rat becomes hyperphagic and gains weight with an increase in visceral fat accumulation $[35,36]$. In this study, adult female rats subjected to prolonged (12-week) ovariectomy were used to assess the metabolic impact of estrogen deprivation with C. comosa treatment in the postmenopausal state. We have previously reported that prolonged ovariectomy leads to the development of systemic metabolic conditions displaying key features of insulin resistance syndrome, such as increased visceral fat content, dyslipidemia, impaired glucose tolerance and decreased insulin-mediated glucose uptake in skeletal muscle [37]. These metabolic alterations in OVX rats were attenuated by estrogen replacement [37]. In this study, we observed that treatment of OVX rats with $C$. comosa extract, at all doses tested (125 to $500 \mathrm{mg} / \mathrm{kg}$ $\mathrm{BW})$, results in significant improvements in whole body insulin sensitivity. Furthermore, a significant enhancement in insulin-stimulated skeletal muscle glucose transport and GLUT-4 expression was evident in the OVX group receiving the highest dose of C. comosa extract. Because the estrogenic activity of $C$. comosa hexane extract has been shown previously [20,21] and its estrogenic activity in vivo is confirmed here by our finding that the reduced uterine weight of OVX animals receiving $C$. comosa extract was reversed in a doserelated manner, it is possible that the beneficial effects of $C$. comosa on glucose metabolism in the estrogendeprived state are attributed by the estrogenic activity of the extract.

Increasing evidence suggests that abdominal obesity and concomitant development of inflammation are major components of insulin resistance, and elevated levels of pro-inflammatory cytokines secreted from expanded adipose tissue can negatively modulate insulin signaling pathways [38]. Recently, it has been reported that treatment with C. comosa powder significantly reduced the expression levels of several pro- inflammatory cytokines in rabbits fed with a high-cholesterol diet [39]. Furthermore, C. comosa extract treatment reduces release of major pro-inflammatory cytokines in the microglia, peripheral mononuclear cells and a pro-monocytic cell line [16,17], highlighting the anti-inflammatory role of $C$. comosa. Thus the finding in this study, that treatment with C. comosa extract reduced the accumulated visceral fat content in OVX rats, suggests that $C$. comosa may improve insulin action by minimizing the source of pro-inflammatory cytokines. Our observation that estrogen-deprivation leads to atherogenic dyslipidemia is consistent with other earlier reports $[40,41]$. C. comosa treatment of OVX rats had favorable effects on plasma lipids, reducing the absolute levels of TC and LDL and the LDL/TC ratios while increasing $\mathrm{HDL} / \mathrm{TC}$ ratios. The reduction in serum LDL cholesterol following treatment with $C$. comosa hexane extract here is consistent with our earlier studies, in which C. comosa extract decreased LDL and increased HDL cholesterol levels by increasing cholesterol excretion and elimination from the body via the feces [42]. Importantly, the decreased serum TC and LDL levels as a result of treatment with $C$. comosa powder in hypercholestorolemic animal were observed without causing liver toxicity [39]. Collectively, we provide evidence that treatment with $C$. comosa extract prevents the development of central adiposity, dyslipidemia, impaired glucose tolerance and skeletal muscle insulin resistance that occur as a result of estrogen deficiency. The mechanisms responsible for its favorable effects may be attributed by its estrogenic and anti-inflammatory properties.

In addition to demonstrating the beneficial effects of C. comosa extract treatment, we have further verified the identity of the active constituent of C. comosa extract and its metabolic effects. Compound 049, or (3R)-1,7-diphenyl-(4E,6E)-4,6-heptadien-3-ol, was found to be the major compound isolated from the C. comosa hexane extract [20]. Its estrogenic activity has been shown both in vitro [20] and in vivo [21], and its relatively weak estrogenic activity in vivo is confirmed here by our finding that the reduced uterine weight of OVX animals was only partially reversed by compound 049 treatment. In the present study, the comparable favorable outcomes were observed for serum lipid profiles, visceral fat accumulation, glucose tolerance and skeletal muscle glucose transport in estrogen-deprived rats treated with either compound 049 or C. comosa extract, whereas the body weight gain and energy intake in OVX rats were significantly reduced only in groups receiving C. comosa extract. This finding suggests that C. comosa extract and compound 049 modulated final body weights and the amount of food intake differently. Although it remains unknown how compound 049 acts 
to prevent the progression of insulin resistance in OVX rats, it possesses weak estrogenic activity which is consistent with the notion that the protective effect of compound 049 against the development of insulin resistance in the estrogen-deprivation condition may be related to other unidentified actions and independent to the estrogenic activity in the regulation of food intake and body weight. Based on the findings that compound 049 treatment leads to a significant improvement in Akt phosphorylation [43] and a reduction in expression of tumor necrosis factor- $\alpha$ [44] in aortic ring of OVX rats, we hypothesize that the mechanism underlying the enhanced whole-body insulin sensitivity and skeletal muscle insulin action in OVX rats by compound 049 treatment may be attributed to its action on tissues known to regulate glucose metabolism. While the opposing effects of the two subtypes of ER in the skeletal muscle have been reported, with ER $\alpha$ inducing and ER $\beta$ inhibiting GLUT-4 expression [34], it has been shown that compound 049 is an agonist for ER, and its biological action is ER $\alpha$ selective [45]. With our finding here that whole muscle GLUT-4 expression is increased following treatment with compound 049, it is likely that compound 049 selectively modulates estrogen receptor and improves insulin action in the skeletal muscle. The mechanisms by which compound 049 enhances wholebody insulin sensitivity and how it affects major metabolic tissues such as the liver and the pancreas are under investigation.

\section{Conclusions}

This investigation indicates that improvements in glucose and lipid metabolism in estrogen-deprived rats manifest following 12-weeks of treatment with $C$. comosa extract, supporting the traditional use of this natural phytoestrogen as a strategy in relieving insulin resistance and its related metabolic defects in postmenopausal women. In particular, C. comosa extract effectively prevented the body weight gain, visceral fat accumulation, abnormal serum lipids, impaired glucose tolerance and skeletal muscle insulin resistance that occur as a result of estrogen deficiency. Importantly, these favorable effects of $C$. comosa extract on lipid profile, visceral fat content and insulin sensitivity are demonstrated to be due to its diarylheptanoid derivative.

\section{Abbreviations \\ C. comosa: Curcuma comosa Roxb; OVX: ovariectomy; Compound 049: (3R)- 1,7-diphenyl-(4E,6E)-4,6-heptadien-3-ol; TC: total cholesterol; HDL: high- density lipoprotein cholesterol; LDL: low-density lipoprotein cholesterol; GLUT-4: glucose transporter 4}

\section{Acknowledgements}

This work was supported by the Program Strategic Scholarships for Frontier Research Network for the Join Ph.D. Program Thai Doctoral degree from the
Commission on Higher Education (to MP) and by grant from the Office of the Higher Education Commission and Mahidol University under the National Research Universities Initiative (to VS) and grants from Mahidol University and the National Research Council of Thailand (to PP) and The Thailand Research Fund (to AS). We are grateful to Professor Prapon Wilairat, Mahidol University for valuable comments on the manuscript.

\section{Author details}

'Department of Physiology, Faculty of Science, Mahidol University, Rama VI Road, Bangkok 10400, Thailand. '2Department of Chemistry, Faculty of Science, Ramkhamhaeng University, Bangkok 10240, Thailand.

\section{Authors' contributions}

MP participated in the animal care and treatment, the glucose tolerance tests and in vitro glucose transport assay, and performed the statistical analysis. VS contributed to the conception and design of the experiments, the glucose tolerance tests and in vitro glucose transport assay, and drafted the manuscript. PP contributed to the conception and design of the experiments, and helped to draft the manuscript. AS contributed to the preparation and quantification of the C. comosa extract and compound 049. All authors read and approved the final manuscript.

\section{Competing interests}

The authors declare that they have no competing interests.

Received: 29 November 2011 Accepted: 30 March 2012

Published: 30 March 2012

\section{References}

1. DeFronzo RA, Ferrannini E: Insulin resistance. A multifaceted syndrome responsible for NIDDM, obesity, hypertension, dyslipidemia, and atherosclerotic cardiovascular disease. Diabetes Care 1991, 14:173-194.

2. Lindheim S, Buchanan TA, Duffy DM, Vijod MA, Kojima T, Stanczyk FZ, Lobo RA: Comparison of estimates of insulin sensitivity in pre- and postmenopausal women using the insulin tolerance test and the frequently sampled intravenous glucose tolerance test. J Soc Gynecol Invest 1994, 1:150-154.

3. Pfeilschifter J, Koditz R, Pfohl M, Schatz H: Changes in proinflammatory cytokine activity after menopause. Endocr Rev 2002, 23:90-119.

4. Sites CK, Toth MJ, Cushman M, L'Hommedieu GD, Tchernof A, Tracy RP, Poehlman ET: Menopause-related differences in inflammation markers and their relationship to body fat distribution and insulin-stimulated glucose disposal. Fertil Steril 2002, 77:128-135.

5. Carr M: The emergence of the metabolic syndrome with menopause. $J$ Clin Endocrinol Metab 2003, 88:2404-2411.

6. López-Candales A: Metabolic syndrome X: a comprehensive review of the pathophysiology and recommended therapy. J Med 2001, 32:283-300.

7. Women's Health Initiative Investigators: Effect of oestrogen plus progestin on the incidence of diabetes in postmenopausal women: results from the women's health initiative hormone trial. Diabetologia 2004, 47:1175-1187.

8. Women's Health Initiative Investigators: Risk and benefits of estrogen plus progestin in healthy postmenopausal women. JAMA 2002, 288:321-333.

9. Lethaby AE, Brown J, Marjoribanks J, Kronenberg F, Roberts H, Eden J: Phytoestrogens for vasomotor menopausal symptoms. Cochrane Database Syst Rev 2007, 17:CD001395.

10. de Kleijn MJJ, van der Schouw YT, Wilson PWF, Grobbee DE, Jacques PF: Dietary intake of phytoestrogens is associated with a favorable metabolic cardiovascular risk profile in postmenopausal U.S. women: the framingham study. J Nutr 2002, 132:276-282.

11. van der Schouw YT, Pijpe A, Lebrun CEI, Bots ML, Peeters PHM, van Staveren WA, Lamberts SWJ, Grobbee DE: Higher usual dietary intake of phytoestrogens is associated with lower aortic stiffness in postmenopausal women. Arterioscler Thromb Vasc Biol 2002, 22:1316-1322.

12. Ingram D, Sanders K, Kolybaba M, Lopez D: Case-control study of phytooestrogens and breast cancer. Lancet 1997, 350:990-994.

13. Adlercreutz H: Phyto-oestrogens and cancer. Lancet Oncol 2002, 3:364-373.

14. Piyachaturawat P, Charoenpiboonsin J, Toskulkao C, Suksamrarn A: Reduction of plasma cholesterol by curcuma comosa extract in hypercholesterolaemic hamsters. J Ethnopharmacol 1999, 66:199-204. 
15. Piyachaturawat $P$, Srivoraphan $P$, Chuncharunee $A$, Komaratat $P$, Suksamrarn A: Cholesterol lowering effects of a choleretic phloracetophenone in hypercholesterolemic hamsters. Eur J Pharmacol 2002, 439:141-147.

16. Jantaratnotai $N$, Utaisincharoen $P$, Piyachaturawat $P$, Chongthammakun $S$, Sanvarinda Y: Inhibitory effect of Curcuma comosa on NO production and cytokine expression in LPS-activated microglia. Life Sci 2005, 78:571-577.

17. Sodsai A, Piyachaturawat $P$, Sophasan $S$, Suksamrarn A, Vongsakul M: Suppression by Curcuma comosa Roxb. of pro-inflammatory cytokine secretion in phorbol-12-myristate-13-acetate stimulated human mononuclear cells. Int Immunopharmacol 2007, 7:524-531.

18. Su J, Sripanidkulchai B, Sripanidkulchai K, Piyachaturawat P, WaraAswapati N: Effect of Curcuma comosa and estradiol on the spatial memory and hippocampal estrogen receptor in the post-training ovariectomized rats. J Nat Med 2011, 65:57-62.

19. Weerachayaphorn J, Chuncharunee A, Mahagita C, Lewchalermwongse B, Suksamrarn A, Piyachaturawat P: A protective effect of curcuma comosa roxb. on bone loss in estrogen deficient mice. J Ethnopharmacol 2011, 137:956-962.

20. Suksamrarn A, Ponglikitmongkol M, Wongkrajang K, Chindaduang A, Kittidanairak S, Jankam A, Yingyongnarongkul B, Kittipanumat N, Chokchaisiri R, Khetkam P, Piyachaturawat P: Diarylheptanoids, new phytoestrogens from the rhizomes of Curcuma comosa: Isolation, chemical modification and estrogenic activity evaluation. Bioorg Med Chem 2008, 16:6891-6902.

21. Winuthayanon W, Suksen K, Boonchird C, Chuncharunee A, Ponglikitmongkol M, Suksamrarn A, Piyachaturawat P: Estrogenic activity of diarylheptanoids from Curcuma comosa Roxb. requires metabolic activation. J Agric Food Chem 2009, 57:840-845.

22. Soontornchainaksaeng $P$, Jenjittikul T: Chromosome number variation of phytoestrogen-producing Curcuma (Zingiberaceae) from Thailand. J Nat Med 2010, 64:370-377.

23. Cortez MY, Torgan CE, Brozinick JT Jr, Ivy JL: Insulin resistance of obese Zucker rats exercise trained at two different intensities. Am J Physiol 1991, 261:E613-E619.

24. Yki-Jarvinen H, Young AA, Lamkin C, Foley JE: Kinetics of glucose disposal in whole body and across the forearm in man. J Clin Invest 1987, 79:1713-1719.

25. Henriksen EJ, Halseth AE: Early alterations in soleus GLUT-4, glucose transport, and glycogen in voluntary running rats. J Appl Physiol 1994, 76:1862-1867.

26. Holloszy JO, Hansen PA: Regulation of glucose transport into skeletal muscle. Rev Physiol Biochem Pharmacol 1996, 128:99-193.

27. Saengsirisuwan V, Perez FR, Sloniger JA, Maier T, Henriksen EJ: Interactions of exercise training and alpha-lipoic acid on insulin signaling in skeletal muscle of obese Zucker rats. Am J Physiol Endocrinol Metab 2004, 287: E529-E536.

28. Park YW, Zhu S, Palaniappan L, Heshka S, Carnethon MR, Heymsfield SB: The metabolic syndrome: prevalence and associated risk factor findings in the US population from the Third National Health and Nutrition Examination Survey, 1988-1994. Arch Intern Med 2003, 163:427-436.

29. Sternfeld B, Bhat AK, Wang H, Sharp T, Quesenberry CP Jr: Menopause, physical activity, and body composition/fat distribution in midlife women. Med Sci Sports Exerc 2005, 37:1195-1202.

30. Bonds DE, Lasser N, Qi L, Brzyski R, Caan B, Heiss G, Limacher MC, Liu JH, Mason E, Oberman A, O'Sullivan MJ, Phillips LS, Prineas RJ, Tinker L: The effect of conjugated equine oestrogen on diabetes incidence: the women's health initiative randomised trial. Diabetologia 2006, 49:459-468.

31. Hodis HN, Mack WJ, Lobo RA, Shoupe D, Sevanian A, Mahrer PR, Selzer RH, Liu C, Azen SP: Estrogen in the prevention of atherosclerosis. Ann Intern Med 2001, 135:939-953.

32. Jones ME, Thorburn AW, Britt KL, Hewitt KN, Wreford NG, Proietto J, Oz OK, Leury BJ, Robertson KM, Yao S, Simpson ER: Aromatase-deficient (ArKO) mice have a phenotype of increased adiposity. Proc Natl Acad Sci USA 2000, 97:12735-12740.

33. Bryzgalova H, Gao H, Ahren B, Zierath JR, Galuska D, Steiler TL, DahlmanWright K, Nilsson S, Gustafsson JA, Efendic S, Khan A: Evidence that oestrogen receptor-a plays an important role in the regulation of glucose homeostasis in mice: insulin sensitivity in the liver. Diabetologia 2006, 49:588-597.
34. Barros RP, Machado UF, Warner M, Gustafsson JA: Muscle GLUT4 regulation by estrogen receptors ERbeta and ERalpha. Proc Natl Acad Sci USA 2006, 103:1605-1608.

35. Latour MG, Shinoda M, Lavoie JM: Metabolic effects of physical training in ovariectomized and hyperestrogenic rats. J Appl Physiol 2001, 90:235-241.

36. Rachoń D, Vortherms T, Seidlová-Wuttke D, Wuttke W: Effects of dietary equol on body weight gain, intra-abdominal fat accumulation, plasma lipids, and glucose tolerance in ovariectomized Sprague-Dawley rats. Menopause 2007, 14:1-8.

37. Saengsirisuwan V, Pongseeda S, Prasannarong M, Vichaiwong $K$, Toskulkao C: Modulation of insulin resistance in ovariectomized rats by exercise training and estrogen replacement. Metabolism 2009, 58:38-47.

38. Luca C, Olefsky JM: Inflammation and insulin resistance. FEBS Lett 2008, 582:97-105

39. Charoenwanthanang P, Lawanprasert S, Phivthong-ngam $L$, Piyachaturawat P, Sanvarinda Y, Porntadavity S: Effects of Curcuma comosa on the expression of atherosclerosis-related cytokine genes in rabbits fed a high-cholesterol diet. J Ethnopharmacol 2011, 134:608-613.

40. Campos H, McNamara JR, Wilson PW, Ordovas JM, Schaefer EJ: Differences in low density lipoprotein subfractions and apolipoproteins in premenopausal and postmenopausal women. I Clin Endocrinol Metab 1988, 67:30-35

41. Jensen J, Nilas L, Christiansen C: Influence of menopause on serum lipid and lipoproteins. Maturitas 1990, 12:321-331.

42. Piyachaturawat $P$, Teeratagolpisal N, Toskulkao C, Suksamrarn A: Hypolipidemic effect of Curcuma comosa in mice. Artery 1997, 22:233-241.

43. Intapad S, Suksamrarn A, Piyachaturawat P: Enhancement of vascular relaxation in rat aorta by phytoestrogens from Curcuma comosa Roxb. Vascul Pharmacol 2009, 51:284-290.

44. Intapad S, Saengsirisuwan V, Prasannarong M, Chuncharunee A, Suvitayawat W, Chokchaisiri R, Suksamrarn A, Piyachaturawat P: Long-term effect of phytoestrogens from Curcuma comosa Roxb. on vascular relaxation in ovariectomized rats. J Agric Food Chem 2012, 60:758-764.

45. Winuthayanon W, Piyachaturawat $P$, Suksamrarn A, Ponglikitmongkol M, Arao Y, Hewitt SC, Korach KS: Diarylheptanoid phytoestrogens isolated from the medicinal plant Curcuma comosa: biologic actions in vitro and in vivo indicate estrogen receptor-dependent mechanisms. Environ Health Perspect 2009, 117:1155-1161.

\section{Pre-publication history}

The pre-publication history for this paper can be accessed here: http://www.biomedcentral.com/1472-6882/12/28/prepub

\section{doi:10.1186/1472-6882-12-28}

Cite this article as: Prasannarong et al:: Improvements of insulin resistance in ovariectomized rats by a novel phytoestrogen from Curcuma comosa Roxb. BMC Complementary and Alternative Medicine 2012 $12: 28$.

\section{Submit your next manuscript to BioMed Central and take full advantage of:}

- Convenient online submission

- Thorough peer review

- No space constraints or color figure charges

- Immediate publication on acceptance

- Inclusion in PubMed, CAS, Scopus and Google Scholar

- Research which is freely available for redistribution 